\title{
Road Asset Management Practices in Ethiopia the Case of Addis Ababa
}

\author{
Yetnayet Bihon Semunigus ${ }^{1,2}$ \\ ${ }^{1}$ Construction Technology and Management, Wolkite University, Wolkite, Ethiopia \\ ${ }^{2}$ Collage of Engineering and Technology, Wolkite University, Wolkite, Ethiopia
}

\section{Email address:}

bihonyetnayet@gmail.com

\section{To cite this article:}

Yetnayet Bihon Semunigus. Road Asset Management Practices in Ethiopia the Case of Addis Ababa. Journal of Civil, Construction and Environmental Engineering. Vol. 5, No. 4, 2020, pp. 61-71. doi: 10.11648/j.jccee.20200504.11

Received: April 30, 2020; Accepted: June 17, 2020; Published: August 10, 2020

\begin{abstract}
Currently, the construction industry is one of the biggest industries in Ethiopia contributing $10 \%$ to the Gross Domestic Product (GDP). It needs to be emphasized that road construction in Ethiopia is the means through which development are achieved. The economic growth of the country depends on availability and utilization of physical infrastructures. Road construction and utilization in Ethiopia are the means through which development strategies are achieved. The development of road construction projects can be enhanced through well-established Asset Management system that will improve tactical and operational decisions by applying the required knowledge to gain wisdom for provision of strategic infrastructures. However, most of the road construction in Ethiopia encounters problems due to lack of proper Asset Management practices. In this respect, this study's objective was to investigate Roads Asset Management practices in Ethiopia the case of AACRA. In order to find answers to the research questions and to achieve the objectives of the study, quantitative and qualitative ways of research adapted. Interviews and questionnaires analyzed quantitatively whereas the desk study analyzed qualitatively explanatorily to assess alternatives, diagnose a situation, and discover new ideas. Accordingly, interpretation and discussion were made on the basis of results. The findings of the study revealed that there is lack of: Asset management system components implementation rated as low with a result of $54.5 \%, 63.6 \%, 64 \%, 82 \%$ and $73 \%$ respectively except condition assessment rated as medium with a result $45.5 \%$, technologies like individual management system implementation in AACRA is in the planning phase as the response of the (7) professional in aggregate revealed, Integration of those management systems also is not there yet. Decision making levels are not explicitly defined in AACRA except programming and budgeting level rated as 54.5\%. $91 \%$ of respondents revealed that there is lack of professional associations, conferences, short courses and $73 \%$ of the respondents disclosed that there is lack of organized asset management department. Some of the specific recommendations forwarded are decision making levels should be explicitly defined, applying different individual management systems and integration of those management systems is necessary and etc. Finally framework were developed for effective and efficient Road Asset Management.
\end{abstract}

Keywords: Asset Management, Individual Management Systems, Data Base, Decision Making, Project Selection and AACRA

\section{Introduction}

Currently, the construction industry is one of the biggest industries in Ethiopia contributing $10 \%$ to Gross domestic product (GDP). This industry is an enormously important part of economic growth of the country. The economic growth of the country depends on availability and utilization of physical infrastructures. Reports indicate that about fiftyeight percent $(58 \%)$ of the federal capital budget of Ethiopia is consumed by the construction industry mainly by the road subsector that generates significant employment opportunities. It needs to be emphasized that road construction in Ethiopia is the means through which development are achieved. Growth in agricultural output, which will constitute the primary basis for growth in the economy of Ethiopia is dependent on transport availability, mainly road transport-, which needs to be efficiently integrated with the rural communities as well as with the 
urban centers. The ERA-, seventeen years RSDP (2014) Assessment Report states Ethiopia has more than 99,522 km in 2014 (an increase of 275 percent) [5]. As a result, the road density per 1000 sq. $\mathrm{km}$ has increased to $90.5 \mathrm{~km}$.

Considering the impacts of road transport on the growth of the economy of the country, the Ethiopian urban and rural road networks needs an effective way of management practice to enhance cost efficiency, serviceability and performance quality. Road construction and utilization in Ethiopia are the means through which development strategies are achieved. In this regard, Road Asset management is essential to sustainably grow, for developing countries like Ethiopia. As Ethiopia is economically growing significantly during globalized age, it needs the entire construction infrastructure to be well integrated to bring a fast and outstanding economic development. It is therefore justifiable to investigate the existing Asset Management practices in the Ethiopian road sub-sector, mainly in the Addis Ababa City Roads Authority.

The development of road construction projects can be enhanced through well-established Asset Management system that will improve tactical and operational decisions by applying the required knowledge to gain wisdom for provision of strategic infrastructures. However, most of the road construction in Ethiopia encounters problems due to lack of proper Asset Management practices. This adversely affects the sustainable development of the road construction sub-sector as well as the economic development of the country. With this understanding Asset Management should increasingly be used to characterize a business-like approach to road network management [16]. Generally Transportation facilities constitute one of the valuable public assets and accounts for a major share of public sector investment worldwide. As being one of the critical facilities it demands better investment decisions for system preservation, expansion and operation based on comprehensive information in a holistic and proactive way [7]. The approach to public works asset management must change, and asset management tools can facilitate this change. It's time to go beyond the current pavement management approach to improve the effectiveness of management practice through the development and implementation of more comprehensive tools, especially those that can be used to better communication with funding authorities. The pavement management system is currently used to help provide mangers with information needed to make management decisions for pavements. The knowledge and information in pavement management can be used directly in asset management [4]. The failure to maintain roads is tantamount to an act of disinvestment, for it implies the sacrifice of past investments in roads. According to the study carried out by The World Bank in the eighty-five developing countries an estimated $\$ 45$ billion worth of road infrastructure has been lost over the past two decades owing to inadequate maintenance. This loss could have been averted with preventive maintenance costing less than $\$ 12$ billion [3]. Therefore, it is very necessary to develop Road Asset Management practices in the pertinent organizations in
Ethiopia.

\section{Literature Review}

The concept of infrastructure management and more particularly of transportation infrastructure management is not new to the world. In the second half of the 20th century, efforts and approaches focused on managing individual transportation infrastructure asset types. Pavement, bridge, tunnel, traffic equipment, congestion, public transportation and various other types of individual management systems have emerged during the last decades. Research in these areas is still ongoing with important findings and continuous progress. Pavement management systems are the oldest and most abundant of these engineering management systems. This is due to the fact that pavements constitute almost sixty percent of the total infrastructure assets managed by transportation agencies [12]. Even though Asset Management (AM) science and practice is not new-agencies in Europe, New Zealand and Australia, and Canada started in the late 1980s and early 1990s. During the last decade of the 20th century, there has been a slow but consistent movement towards a more holistic approach to the management of these assets. Transportation agencies in the United States (US) and around the world have begun to acknowledge the merits of a more comprehensive methodology for managing their infrastructure. This holistic way of dealing with the management of transportation assets, coupled with more "business-like" objectives has led to what is today commonly known as Asset Management [11].

According to L. Ma, Y. Sun and J. Mathew, (2007) "An Asset Management process is a set of linked (often interrelated) activities and the sequence of these activities that are necessary for collectively realizing Asset Management goals, normally within the context of organizational structure and resource constraints". From the joint committee of AASHTO - AGC ARTBA, Asset Management is defined as the strategic approach to the optimal allocation of resources for the management, operation, preservation, and maintenance of infrastructure [14]. The concept of AM combines engineering, economic principles, and sound business practices to support decision making at the network and project level [17]. A simple working definition of AM would be: first, assess what you have; then, assess what condition it is in; and lastly, assess the financial burden to maintain it at a targeted condition (17). Asset management comprises the entire process from programming and planning to preservation of the system and is characterized by a solid policy frame work, measurable objectives, and continuous performance monitoring. Thus, AM provides a framework for handling both short- and long-range planning." In addition AM applies the principles of engineering, business management, and economics through computer aided technology [4].

As stated by OECD, (2001) asset management system generally include: inventory information for the asset and condition measures; values of condition of the asset; a performance prediction capability; ensure data integrity, enhance data accessibility and provide data compatibility; all 
relevant components in life-cycle cost analyses; enable the removal of outdated systems and unproductive assets; consider both system and project optimization; report useful information on a periodic basis, ideally in real time; and facilitate iterative analysis processes that can be performed on a regular basis [15]. In its most general sense, AM is a business approach designed to align the management of asset - related spending to corporate goals. Typically, utilities adopt an AM approach to either reducing spending, more effectively manage risks, or drive corporate objectives throughout an organization [19]. Simply, AM is a corporate strategy that seeks to balance performance, cost and risk in order to ensure the optimum utilization of asset. Achieving this balance requires the alignment of corporate goals, management decisions, and technical decisions [20]. International Data Corporation found that companies practicing AM lowered their annual costs by nearly twenty percent on average. With AM, they can track all the costs associated with an asset including initial price. Depreciated values, service costs, add-on equipment etc. [17].

According to FHWA (1999), the basic generic AM system components are the followings: Goals and policies; Asset inventory; Condition assessment; Performance monitoring; Alternatives analysis/program optimization; Short/long - range plans: and Program implementation [7]. There are various decision making levels that represent different perspectives on the system, ranging from very specific, detailed, and project oriented views to generalized, comprehensive and strategic ones. According to Haas. R et al, (1994), Hudson. W. k et al,(1997) and AASHTO, (2001) the decision levels pertaining to $\mathrm{AM}$ as identified in literature are: the strategic level, network level, and project level [12, 13, 1].

According to V. dot, (2004) data collection methods are: Manual; automated; semi-automated; and remote collection. The data management or storage media employed can be paper forms (still in use in many agencies), hard disks, magnetic tapes, CDs, DVDs and combinations of thereafter [2]. Electronic data are the easiest to share and can exist in various forms such as text, graphics, photos, and videos. They can be stored either in flat files or in structured database files (relational, object-oriented), which can be stand-alone or part of a database system [11]. According to FHWA, (2001) data integration alternatives include two main approaches: a fused database and many interoperable databases. In the first case the integration strategy leads to the creation of one database that contains all integrated data; in the second case existing or newly created databases are linked together and the integration of the data is achieved with the use of queries that provide a view of the linked data [8]. For example, various state department of transportation (DOT) offices of the US have used GIS and other geospatial tools for data integration [10]. GIS software and related functionalities can alternatively be incorporated in the databases as external software that enhances the analytical and reporting capabilities of the system [9].

\section{Methodology}

In order to find answers to the research questions and to achieve the objectives of the study, quantitative and qualitative ways of research adapted. Mixed-method research seems to be appropriate and is helpful in gaining a better understanding through an in-depth study of the new phenomenon based on its qualitative and quantitative aspects of the study. The overall approach followed was; having established the basis of the research, necessary data were collected, analyzed, and conclusions, recommendations and frameworks were made based on the findings. The methods of data collections employed for the research are: - desk study, questionnaire, and interview. The three tools were used for triangulation. The study then employed both inferential statistics for the data analysis and the Qualitative research of explanatory type was adopted in order to diagnose a situation, assess alternatives, and discover new ideas.

The target population were pertinent Government organization on the road sector in Ethiopia namely Ethiopian roads Authority (ERA) and Addis Ababa city Roads Authority (AACRA). The Research focused on Addis Ababa City Roads Authority due to its accessibility and Vulnerability to Asset deterioration and damage as well as Addis Ababa is the home of Africa Union, United Economic Commission for Africa (ECA), etc. The sampling techniques was used to select representatives of the population and was purposive sampling. Accordingly the questionnaire is distributed to all asset management professionals and data collectors working in Road Asset management directorate in AACRA purposively. Whereas the interview is made using purposive sampling method to team leaders and data base directorate director only, since the population is very small. Desk study were undertaken for both Addis Ababa city Roads Authority (AACRA) and Ethiopian Roads authority (ERA) in order to share some of the experiences.

\section{Results and Discussion}

\subsection{Desk Study}

Desk study was chosen as one of the instruments to assess and obtain actual data about the practices of road Asset management system from relevant studies, data's and documents.

In 1951, when the Ethiopian Roads Authority was established, the total road network amounted to $6,400 \mathrm{~km}$. This network was built mainly during Italian invasion. By 1997 the road network had grown to $26,550 \mathrm{~km}$, of which $3,708 \mathrm{~km}$ were paved. As a result of investments under Road sector development programs (RSDP) of I, II, III and IV). The country's road network has increased from $26550 \mathrm{~km}$ in 1997 to $99,522 \mathrm{~km}$ in 2014 (an increase of 275 percent). As result, the road density per 1000 sq. $\mathrm{km}$ has increased from $24 \mathrm{~km}$ in 1997 to $90.5 \mathrm{~km}$ in 2014. Also substantial improvement has been registered in the condition of the country's road network. The proportion of road network in good condition increased from $22 \%$ in 1997 to $70 \%$ in 2014 [5]. 
According to ERA, 1997 and 2015 the surface composition of roads in ERA in 1997 was $77 \%$ of unpaved or gravel roads and $23 \%$ of Asphalt or Paved roads whereas in 2015 was 51\% gravel or unpaved and $49 \%$ paved or Asphalt. It can be calculated from above description that the percentage share of asphalt roads has increased by about 113\% from 1997 to 2015 and correspondingly, the percentage share of gravel roads has reduced by about $34 \%$ between the two periods.

Past failure to undertake adequately funded, planned and managed maintenance programs have led to the situation where the massive capital investments of the Road Sector Development Program (RSDP), have become necessary. However, the lessons of the past have been well learned by the Government and the Ethiopian Roads Authority (ERA), and much attention is now being focused on maintenance tasks [5]. The total federal road network of which is being administered by ERA has reached to $26,857 \mathrm{~km}$ as of July 2014. Overall road network in Ethiopia has been increasing on the average by $3.2 \%$ yearly.

Improving the condition of the road network is still a challenge. The improvement of the road network in the country is only changing the condition of the network slowly. In the first year of RSDP, $52 \%$ of the road network was found to be in poor condition and only $22 \%$ was in reasonably in good condition. Owing to on-going rehabilitation, upgrading and maintenance intervention under the program, the proportion of the road network in good condition has increased to 50 percent and the road in poor condition has declined to $22 \%$. The proportion of roads in good condition has overtaken the proportion of roads in poor condition from 2004 onwards and particularly the last two years owing to a massive intervention in terms of rehabilitation, upgrading and maintenance on major roads. The proportion of road network in good condition increased from $22 \%$ in 1997 to $70 \%$ in 2013 . Another observation is that the roads in fair and poor condition are consistently declining shifting to good condition since the year 2002 .

The Ethiopian Roads Authority (ERA) was restructured to sustain and accelerate quality improvement of the federal road network. A new Road Asset Management Department, headed by Deputy Director General has been set up recently with responsibility for road asset management coordination. Ten Road Asset Management Coordination Directorates have been set up located in different parts of the country and administer roads under their respective jurisdiction. The Road Asset Management Department will be responsible for short and long term road network maintenance plan to ensure mobilization of adequate resource for the maintenance of the network and the provision of roads with acceptable operating condition for vehicles. The department is responsible to produce effective network maintenance plan using standard road asset management tools such as Pavement Management System (PMS) and Highway Development and management Model (HDM 4). The Department is also responsible for functional classification and numbering of the road network and for data base of the network using PMS and HDM 4 and other appropriate tools. The Ethiopian Roads Authority have already implemented an Asset Management system. They have been utilizing individual management systems, the most predominant among them being pavement, bridge management systems and Highway development and management tool (HDM4). Other systems include safety management system. ERA has established Pavement Management System to systematically manage the road network; the PMS system has incorporate road condition data collection equipment and software for both paved and unpaved roads. In addition ERA has established a Bridge management system encompasses all engineering and management functions that are necessary to efficiently carry out bridge operations. These include data collection and its management, inspection, planning and programming, construction and maintenance. The level of integration of these individual systems within an overall Asset Management framework is still in the planning phase in ERA. ERA collects data both automated and manually. Automated equipment's that ERA currently using are Hawkeye 1000, Hawkeye 2000 is not fully operational and falling weight Deflecto meter (FWDM). In Automated data collection some of state of the art equipment including Automated Road Analyzer (ARAN), Heavy Weight Deflectometer (HWD) and Weigh in Motion traffic equipment are used to assess the structural and functional conditions of the pavement. From the ARAN testing: roughness (ride), rut depth, surface macro texture and surface distress results were collected. From the HWD testing: layer modulus and remaining structural life were calculated and reported. From the Weigh in Motion study the current axle loading was determined for evaluating remaining life. Decisions on what data to collect are based on staff experience, widely accepted data collection standards and specific needs of individual management systems, the pavement and bridge data are kept in separate databases.

The road way asset data is utilized for selection between two competitive projects. The most important data used to select projects in ERA are location, structural and functional conditions. The PMS gives an opportunity for ERA to identify appropriate treatment for each block based on distress types and severity. The system also includes a cost module that is used to calculate costs for the candidate projects. The appropriate offices at ERA use cost-benefit analysis and project-to-project comparisons to determine the final list of prioritized candidate projects.

The basic generic Asset Management components are Goals and policies, condition assessment performance monitoring, Alternative assessment and program optimization, short and long range plan and program implementation this components are implemented in ERA in moderate way. Goals and policies regarding asset management has been practice as it is reported in ERA modernization report they have planned to formulate policy, to create an asset management integrated system, asset management data base, asset inventory, asset valuation and standardize reporting data exchange and short term and long term goals has been set.

Asset Management implementation within the Addis Ababa City Roads Authority is at the planning stage. They 
are currently organizing the Asset management office under the Road Asset Management Vice President Director General. Sub cities in Addis Ababa are designated under each road asset management directorate. Under the Central RAMD, designated offices are: Kirkos, Lideta, Arada and Ring Road and the offices under Eastern RAMD are: Bole sub city and Ring road, the Southern RAMD are: Nifasilk Lafto, Akaki kality and Ring road, offices designated under Northern RAMD are: Gulele, Yeka and Ring road. In the past, the Addis Ababa City Roads Authority had utilized pavement management system but the system failed due to lack of trained professionals, poor systematic follow up and underutilization of the system. Since 2014-2016 G. C the data were manually collected stored in excel sheet. Currently they are in the process of applying Pavement management system and Maintenance management system utilizing the Kyoto model (Japanese government cooperation). This model will help AACRA to make decision scientifically based on performance curve or past results of the pavement, helps to store and retrieve pavement inventory and condition data, to predict pavement deterioration through its pavement deterioration prediction model and for most it will help the organization to cross check its policy based on bench mark evaluation and investigation inspection data if the organization developed an asset management policy. Along with the integration of the individual system a central database for these individual systems within an overall Asset Management data base which integrate and use to retrieve for decision making purposes is still at the planning phase. But in the process of setting asset management system AACRA is planning to set up an asset management data base. Asset Management data base which is established in AACRA is excel sheet which is traditional managing and storing asset data. The history of the roads in the organization is not defined and evaluated and not known explicitly. But currently they are developing an asset management database which will be developed under Kyoto model pavement management system even if the PMS has own data storage. AACRA had been collecting road data manually since 20142016 G. C. Previously data collection were not practiced and AACRA did not know the conditions of the roads under their jurisdiction other than budgeting for construction of new roads. Currently they are in training and trial of applying automated road collection equipment called pavement condition survey vehicle. In ACCRA project selection is done based on the economic, political and social aspects of the roads in network and in addition the severity of the asset is also taken in to consideration while selecting project for funding and implementation. But there is no scientific way of analyzing the condition of the roads for implementation and funding by using different models and management systems. Still now they make decisions based on traditional way. Decisions made at the different levels of Asset Management are heterogeneous and the supporting data needs are bound to be quite different. Decision making levels are not explicitly defined in AACRA road asset management directorate but they made decisions on the network level.

\subsection{Questionnaire and Interview}

The study was focused on Investigation of Road Asset Management practices in Ethiopia considering AACRA as a case study. Accordingly, the scope of this research is limited within the AACRA Road Asset Management Directorate. In this regard all Asset management professionals, team leaders and Management bodies were considered in this study survey. The number of participants was 15 all the AACRA Road Asset Management Directorate professionals, team leaders and management staff. A total of 15 questionnaires were distributed: 11 were distributed for Asset management professionals and team leaders, 3 to data collectors, 1 for Road Asset management Data Base Director General. Out of the distributed 15 questionnaires, 11 professionals and team leaders responded to the survey which were $11(73.33 \%), 1(6.67 \%), 3(20 \%)$, from Road asset management Database Director General and Data collector, respectively. This is overall response rate of $100 \%$, which acceptable for the analysis of the data. The details of respondents' response are summarized in Table 1 and Table 2 show respondents' position and distribution of questionnaires and response rates respectively.

The responses about Asset Management implementation revealed that most of the responding professionals, team leaders and data collectors seven (7) in aggregate are still at the planning phase. Furthermore four (4) of the respondents indicated that they have already implemented an Asset Management system. The responses also revealed that most of the individual management systems have not been utilized, the most predominant ones among them being: - pavement, bridge, and maintenance management systems. Other systems include safety (SMS), congestion (CMS) management systems. ACCRA has now in the development of the pavement management system with Kiyoto Model (JICA). Furthermore most of the responding professionals revealed that the level of integration of these individual systems within an overall Asset Management framework does not exist yet. Table 3 below shows respondent rates.

Table 1. Respondent's position and Distribution of questionnaires.

\begin{tabular}{lllll}
\hline Organization & $\begin{array}{l}\text { Road asset management Vice } \\
\text { president }\end{array}$ & $\begin{array}{l}\text { Road asset management } \\
\text { database director }\end{array}$ & $\begin{array}{l}\text { Road Asset management } \\
\text { professionals and team leaders }\end{array}$ & $\begin{array}{l}\text { Data collectors } \\
\text { Total }\end{array}$ \\
\hline AACRA & - & 1 & 11 & 3 \\
Total & - & 1 & 11 & 3 \\
\hline
\end{tabular}


Table 2. Distribution of questionnaires and responses rate.

\begin{tabular}{lllll}
\hline Respondents & $\begin{array}{l}\text { Distributed } \\
\text { questionnaire } \\
\text { in number }\end{array}$ & $\begin{array}{l}\text { Semi Structured } \\
\text { interview in } \\
\text { number }\end{array}$ & $\begin{array}{l}\text { Returned Semi } \\
\text { structured interviews and } \\
\text { questionnaire in number }\end{array}$ & $\begin{array}{l}\text { Questionnaire and } \\
\text { Semi structured } \\
\text { interviews,\% }\end{array}$ \\
\hline Road asset management Vice president director general & - & - & - & - \\
Asset management professional/team leader & 8 & 3 & 11 & 73.33 \\
Road Asset management database director general & & 1 & 1 & 6.67 \\
$\begin{array}{l}\text { Data collector } \\
\text { Total }\end{array}$ & 3 & - & 3 & 20 \\
\hline
\end{tabular}

Table 3. Respondents rate for Asset Management Implementation.

\begin{tabular}{lll}
\hline Response Types & Number of Respondents & Percentage (\%) \\
\hline Yes & 4 & 36.36 \\
Planning & 7 & 63.63 \\
Don't Know & 0 & 0.00 \\
Total & 11 & $100.00--$ \\
\hline
\end{tabular}

Based on the Literature Review the respondents rated the components of Asset management system; goals and policies, asset inventory, condition assessment, performance monitoring, alternatives analysis/program optimization, short/long range plans and program implementation of Asset Management Systems. Each of the above criterion is explained below and the results are depicted in Figure 1.

Goals and Policies: - As resulted during the survey 54.5\%, $18.2 \%$ and $27.3 \%$ of the respondents evaluated the implementation rate of the Goals and Policies component as low, medium and high (low and very low categorized under low, high and very high categorized under as high) respectively.

Condition Assessment: - These result showed that 27.3\%, $27.3 \%$ and $45.5 \%$ of the respondents rated Condition Assessment component as low, high and medium respectively.

Performance Monitoring: - Component Implementation rated as $63.6 \%, 18.2 \%$ and $18.2 \%$ as low, medium and high respectively.

Alternative Assessment and Program optimization: Alternative assessment and program optimization component of asset management system rated by the respondents were $64 \%, 0 \%$ and $36 \%$ as low, high and medium respectively.

Short and Long Term Plan: - In this case, short and long term plan component of asset management were rated as $82 \%, 9 \%$ and $9 \%$ respectively as low, high and medium.

Program Optimization: - Program optimization was rated by respondents as $73 \%, 0 \%$ and $27 \%$ in respect of low, high and medium. Figure 1 graphically presents, Asset management components implementation rate. When asked to report on their defined decision making levels, most of the responding professionals in AACRA indicated that they have not explicitly defined levels in line with the criteria as defined in the literature. The main identified levels were programming and budgeting. It confirms that the organization had focused its attention to these intermediate levels mostly programming and budgeting level connecting the generic strategic decisions of the strategic level to the actual project implementation at the project level. Figure 2 below illustrates the decision making levels.

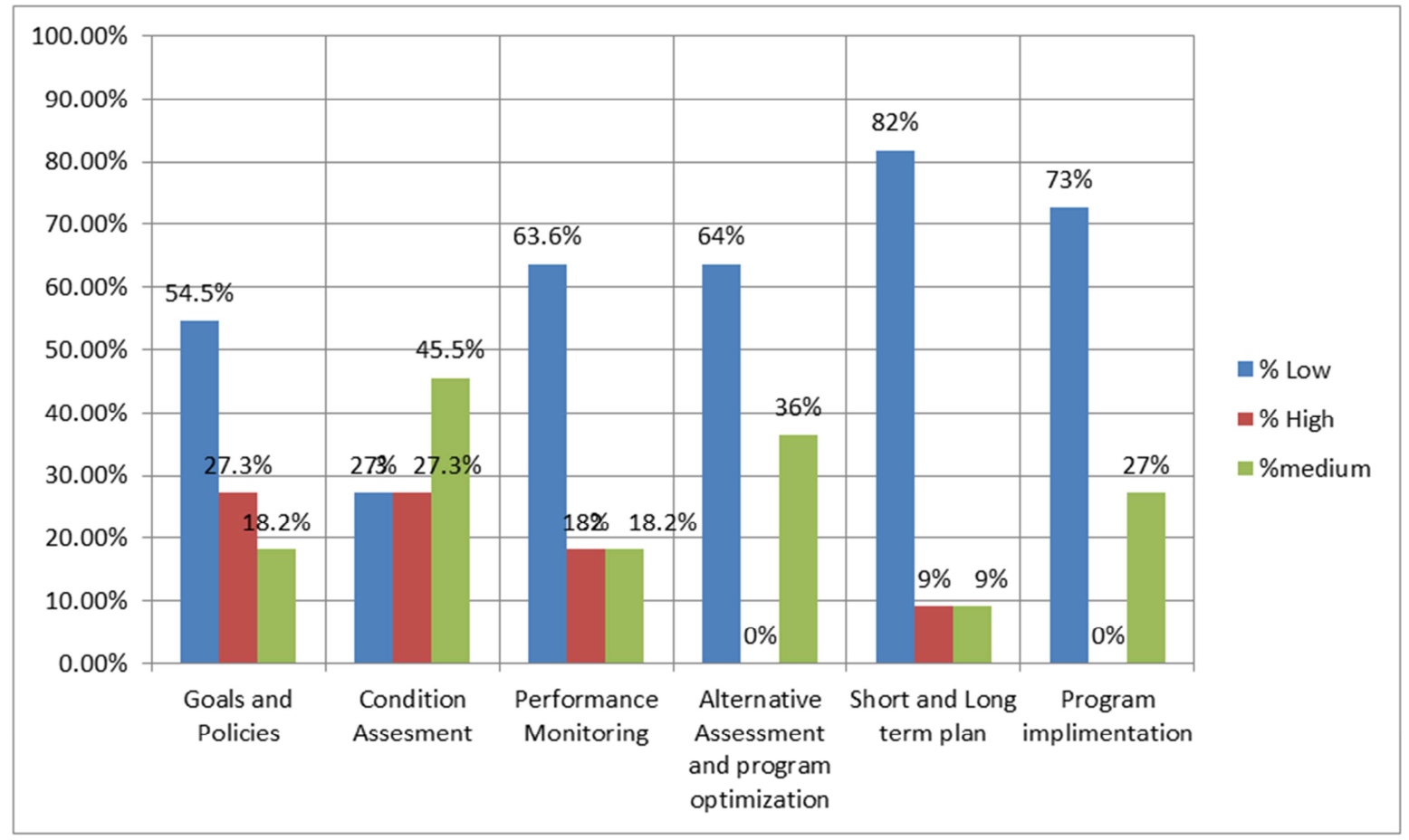

Figure 1. Asset Management System Components implementation. 


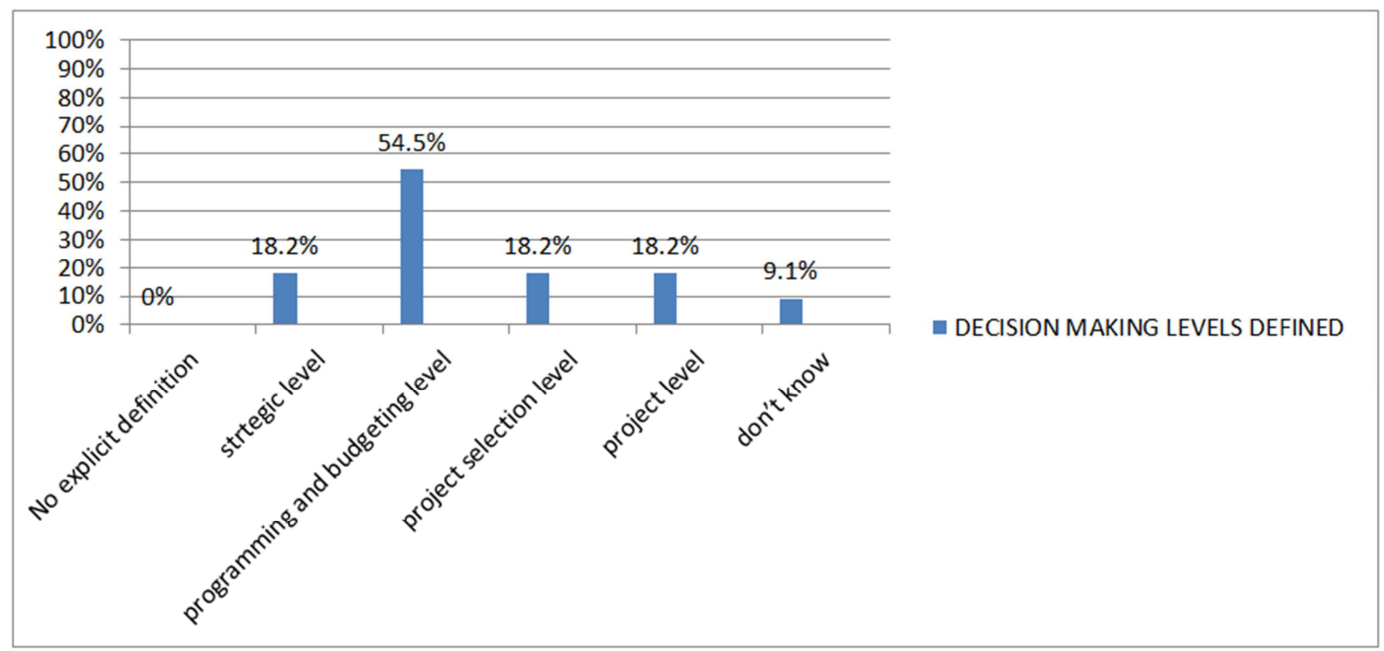

Figure 2. Decision making levels.

However, most of the respondents revealed that all types of maintenance are not practiced according to the data collected whereas some of the respondents reported that AACRA is planning to implement preventive, routine, and periodic maintenance and also rehabilitation. Figure 3 below present's data collection methods used in respect of manual, automated and both and Figure 4 presents types of roadway assets. According to most of the respondents, the condition of the assets assessed is always on AACRA road network. However, AACRA neither identified nor formally documented any relationship between the roadway data collected to support project selection and the decision made. The respondents were also asked to provide information about their rationale behind data collection. These results are summarized in Figure 5 below. The responses confirmed that their data collection still base on decisions on past practices and staff experience. However, some respondents also noted that data collection practices have been based on data collection standards and input requirements of utilized management systems or other defined decision processes.

Problems and challenges that arise during the implementing of Road Asset Management were assessed to answer the research question number three. Seventy three (73\%) percent of the respondents explained that there is lack of an organized Road asset management department and ninety one $(91 \%)$ percent of the respondents said that there is lack of professional associations, conferences and short courses to get updated in state -of the- art techniques of asset management is one of the problems. This implies that if AACRA does not have an organized Asset management office; it lacks influence on the potential to improve the physical performance and function of a road and its systems, as well as to increase the users' level of satisfaction, in order to minimize life cycle cost of the Authority's asset and to improve efficiency in maintained and operating of the same.

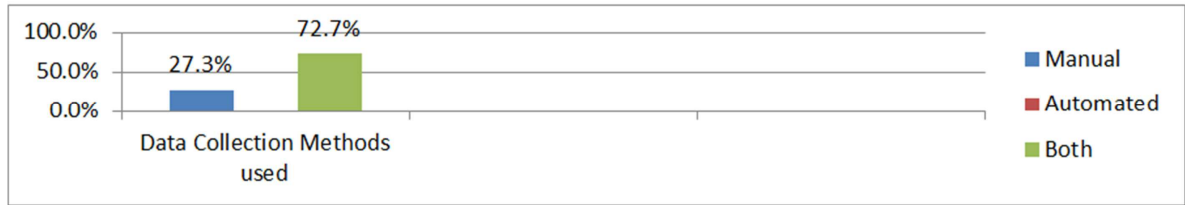

Figure 3. Data collection methods used.

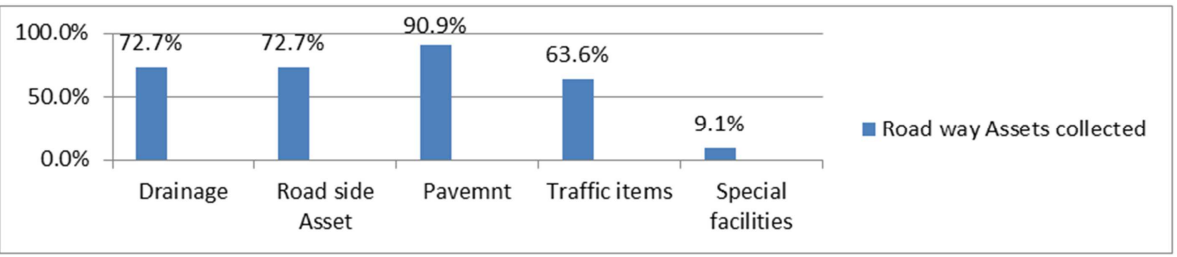

Figure 4. Types of Roadway Asset Collected.

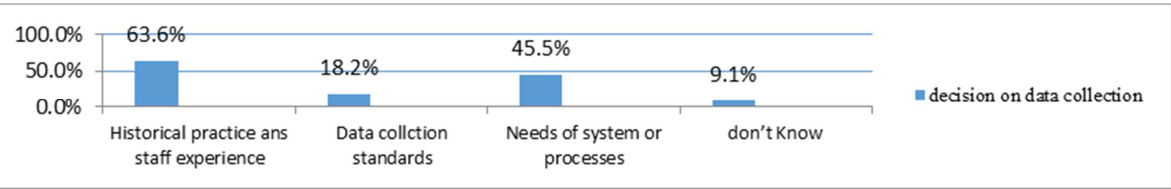

Figure 5. Data collection rational decision. 
The respondents rated different factors as causes of problems in Asset management implementation. As shown below in Figure 6, the asset system problem are: - financial challenges, over all asset system problem, organizational challenges, professional competency and integration are the major causes of the problems. However, to prevent or to minimize the above explained problems and challenges it needs to minimize the root causes of the problems.

To get competent professionals in Road Asset management universities have to provide intensive courses in Asset management by establishing appropriate departments at graduate and under graduate level and share experience from other countries and professional associations how to develop this competency. Integration with pertinent government organization need to be developed. Fortunately a Federal Integrated Infrastructure Coordinating Agency (FIIDCA) [6] has been established recently which is a good start. In this regard, AACRA should take the initiative and need to get long term plan that will make it easy to include in the inception of the project and design. (As mentioned in the foregoing, AACRA) has five recently established regional office for effective and efficient road resources management. The regional offices will be accountable to the Deputy Director General of AACRA for road access. The new offices will increase the capacity of the Authority in securing and managing the roads, enabling the Authority to interact more with stakeholders; sub cities, Ethio - Telecom, Addis Ababa Water and Sewerage Authority and Ethiopian Electric Utility.
AACRA is also working on a drainage master plan with ETB 62.5 million loan from the World Bank. And lack of political awareness regarding asset management system practice has been costing countries enormously, since delays in executing maintenance generally leads to increased severity of deficiencies (i.e., to poor or very poor conditions) and can eventually lead to a need for complete pavement rehabilitation or reconstruction in later years. Addis Ababa City Roads Authority needs its top-level agency commitment (at the very highest levels) in support of asset management to be apparent in every case. Asset management officials should identify and need to change the culture of the organization to think of asset management as a key business area and as a key challenge.

The organization had a Management position or office responsible for asset management should work on creating the organizational culture. Financial challenge is the major cause of problem rated as $64 \%$. The experience of other countries found, asset management practices and processes have been used successfully to obtain funding for transportation infrastructure, when competing for funds with other government programs, and even during budget declines if the asset management system used fully and operational it will help to minimize financial challenges. Overall asset management system problem is the major problem rated $55 \%$ it can be averted by creating awareness of decision makers and political official that how much benefit will be saved if the system is operated even if the costs are accrued. Figure 6 presents the causes of problems for Asset management implementation in AACRA.

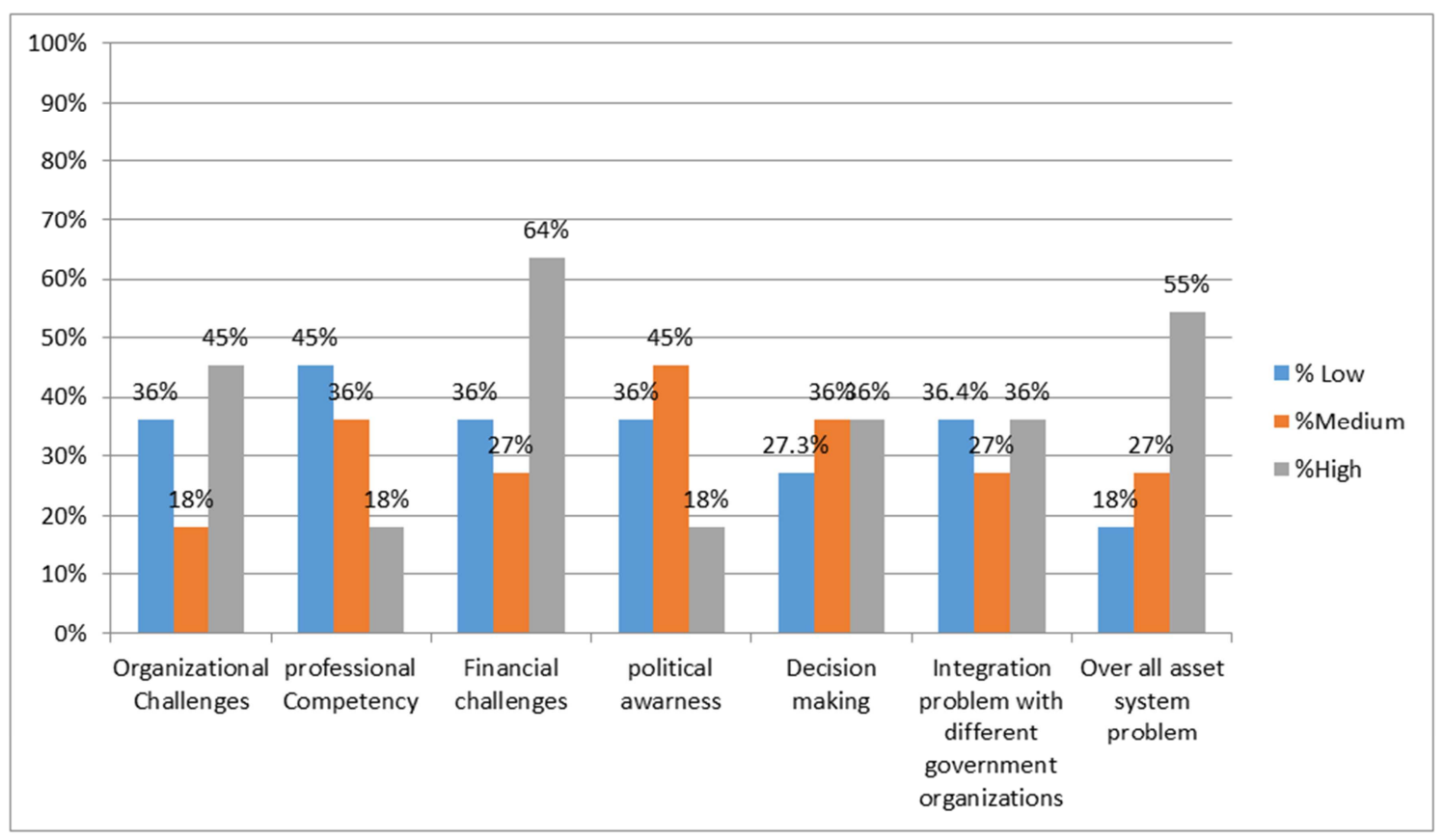

Figure 6. Causes of problems for Asset management implementation.

\subsection{Interview}

According to interview made with Road asset management Data Base Directorate Director, the data management in ACCRA since 2014 to 2016 G. C is done as follows: - data collected in paper format converted in - to Excel sheet and stored. The same answer is given by the team leaders who made an interview with the researcher. Integration of road asset management system is an application of suitable asset management software which will integrate all individual road 
management systems. According to the Road Asset Management Directorate Director, the organization has neither applied asset management integration software nor individual management systems until the period of the interview. But according to the interview with the team leaders the organization is developing a model called Kyoto Model with Japanese government cooperation called (Jica). There is also planning to integrate those models developed by Jica which are in separate asset management data bases.

The next question forwarded to the interviewees was to rate the importance of identified roadway assets for selection in respect of location, Attributes/characteristics, structural condition, functional condition, initial agency costs, life-cycle costs, usage and customer or user feedback. The Team leaders pointed out that the project selection between two projects is made mostly based on location, structural condition, budget and functional condition. Whereas the Asset Management Directorate Director informed that the most important factors are location, structural and functional condition. A project which has economic, political and social impact will be given priority. For example if the road from Bole Airport to 4- Arat kilo has 10 pot holes where as the road from Mexico to Sarbet has 20 potholes, the priority will be given to the former rather than to the latter because of its political use. Since many dignitaries are using the Bole-Arat kilo Road. Similarly, the roads around Merkato area will get priority because of economic influence. Generally location is ranked first because political and economic importance. The results confirm to common sense, personal judgments and also show that the responding officials had predominantly the same perception of the data that would prioritize project selection between different assets.

A set of rehabilitation and maintenance alternatives may be developed to meet objective, and the alternatives analyzed to determine the optimal set of alternatives (e.g., the set of alternatives that can be used to meet the specified objective at the lowest life cycle cost). TAM best practice will use methods and criteria that reflect stated policy objectives, performance measures and targets to prioritize projects. Also, projects will be evaluated in terms of realistic estimates of life cycle costs, benefits and performance impacts. According to Team leaders and the Data base Directorate Director there is no explicit way of analyzing alternatives and get a decision based on scientific way of analysis like life cycle cost. Similarly, there is no economic evaluation method used to evaluate the pavement economic viability.

AACRA does not know the value of the asset in their network rather than doing the straight - line depreciation. Government accounting procedures were viewed in several cases as inappropriate for assigning value to assets and as a driver for asset management decisions. In these cases, asset management approaches were used to assign a value to assets. Asset management systems are much more appropriate for determining asset valuation than are straight-line depreciation accounting rules.

\subsection{Summary of Findings and Discussion}

In this section, the findings of the survey and desk study were compared, summarized and discussed from the perspectives of literature review about Road asset management practice.

There is no Asset Management components implementation practice in its fullest sense in Addis Ababa Roads Authority like Goals and policies which guides how to practice asset management system. Condition assessment of the road in their network should be explicitly defined and categorized, performance monitoring in which most common asset management performance measures relate to condition, function, and capacity of the assets. In some cases, these categories of performance characteristics could provide the basis for cross-asset evaluation and investment prioritization. Alternative analysis, program optimization and short and long term plans also are not practiced well in the organization. Road Asset Management implementation in AACRA is still at its initial stages. Most of individual management systems are not used in the organization however, the organization is currently planning and developing. Data collection methods used in AACRA are both manual and automated but the automated method of data collection is on trial base in AACRA. The integration of individual management systems is not there in AACRA since they do not have the individual management systems in the first place but they are planning to develop. The same is true for roadway inventories and databases.

The data management method used in AACRA is traditional way of storing the collected data manually on paper based then converted in to Excel sheet and stored in computers but roadway inventories and database is not available yet. However, currently they are planning and developing individual management system and automated data collection methods. The most important criteria used for project selection in AACRA are Location, Structural severity, budget and function are used but there is no explicit way of analyzing the severity. Mostly it is done by personal judgment. Data collection decisions in AACRA are predominantly based on past practices and personnel experience. But they do not mostly base their data collection decisions on data collection standards and input needs of management systems or processes behind the rationalization of data collection. AACRA do not formally identified and documented existing links between the data they collect and the project selection decisions they support. Similarly, asset management approaches are not used to assign a value to assets. Asset management systems are much more appropriate for determining asset valuation than straight-line depreciation accounting rules. Decision making levels are not explicitly defined in AACRA rather than the Programming and budgeting level which connects the strategic level to the actual project implementation at the project level.

Asset management training has been an important aspect of asset management strategy. It is noted that a good asset management program requires knowledgeable staff capable of understanding the data-collection process and what the data mean but AACRA lacks it. There is no very active asset management professional associations and user groups, spearheaded by local officials, have no developed asset management materials, guide lines and training programs 
aimed at both public officials and practicing transportation professionals. The absence of a specific organization creates difficulty in asset management practice. Organizational challenges, financial challenges, over all Asset Management system, Political Awareness and professional competency are the major causes of problems for road asset management practice in AACRA. It needs top-level agency commitment (at the very highest levels) in support of asset management to be apparent in every case. Asset management officials should identify and need to change the culture of the organization to think of asset management as a key business area as a key challenge. The organization had a management position or office responsible for asset management should work on creating the organizational culture. As the experience of other countries found, asset management practices and processes have been used successfully to obtain funding for transportation infrastructure, when competing for funds with other government programs, and even during budget declines if the asset management system used fully and operational it will help to minimize financial challenges. And also competent professionals in the area have to be produced. This can be done by opening Asset management department undergraduate and graduate levels and sharing experience from other countries professionals or associations on how to develop competency. Finally, the result obtained in the survey and desk study is analyzed and discussed with the comparison of literature review. Based on this analysis and discussion, conclusion and recommendation given.

\section{Conclusion}

The main objectives of this research was to study the Road Asset Management (RAM) and the existing practices taking the Addis Ababa city Roads Authority (AACRA) as a case study and make recommendations and to prepare frameworks based on the findings.

Organizational challenges, financial challenges, Political awareness, over all asset management system and professional competency are the major causes of problems for road asset management practice in AACRA. There is lack of Asset Management components implementation practice in its fullest sense in Addis Ababa Roads Authority. The implementation stage of an asset Management system is still at the planning stage. Most of the individual management systems have not been utilized, data collection decisions were not based on standards and input needs of management systems or processes behind the rationalization of data collection. The AACRA do not still formally identified and document existing links between the data they collect and the project selection decisions they support. The main problems faced in applying asset management practice are lack of organized Asset management department, lack of professional associations, conferences, and short courses to acquire state-of-the- art techniques of Road asset.

\section{Recommendations}

Higher educational institutions need to open Asset Management department in Ethiopia and Conferences need to be prepared to provide trainings and short courses for the employee. Creating integration with pertinent government organization like; Ethiopian Electric Utility, Ethiotelecommunication Authority, Water and Sanitary Authority, etc. to preserve the asset from excavation and damage. Toplevel management in the organization should be committed in support of asset management to be apparent in every case. Asset management officials should identify and need to change the culture of the organization to think of asset management as a key business area. Up-to-date condition of the asset should be surveyed and inventoried and database should be created to know the history of the roadway assets and should create Asset Management Practice Manuals and Guidelines.

The findings from the literature review, the survey analysis and Desk study allowed for the recommendation of the framework for effective and efficient Asset management as illustrated on Figure 7.

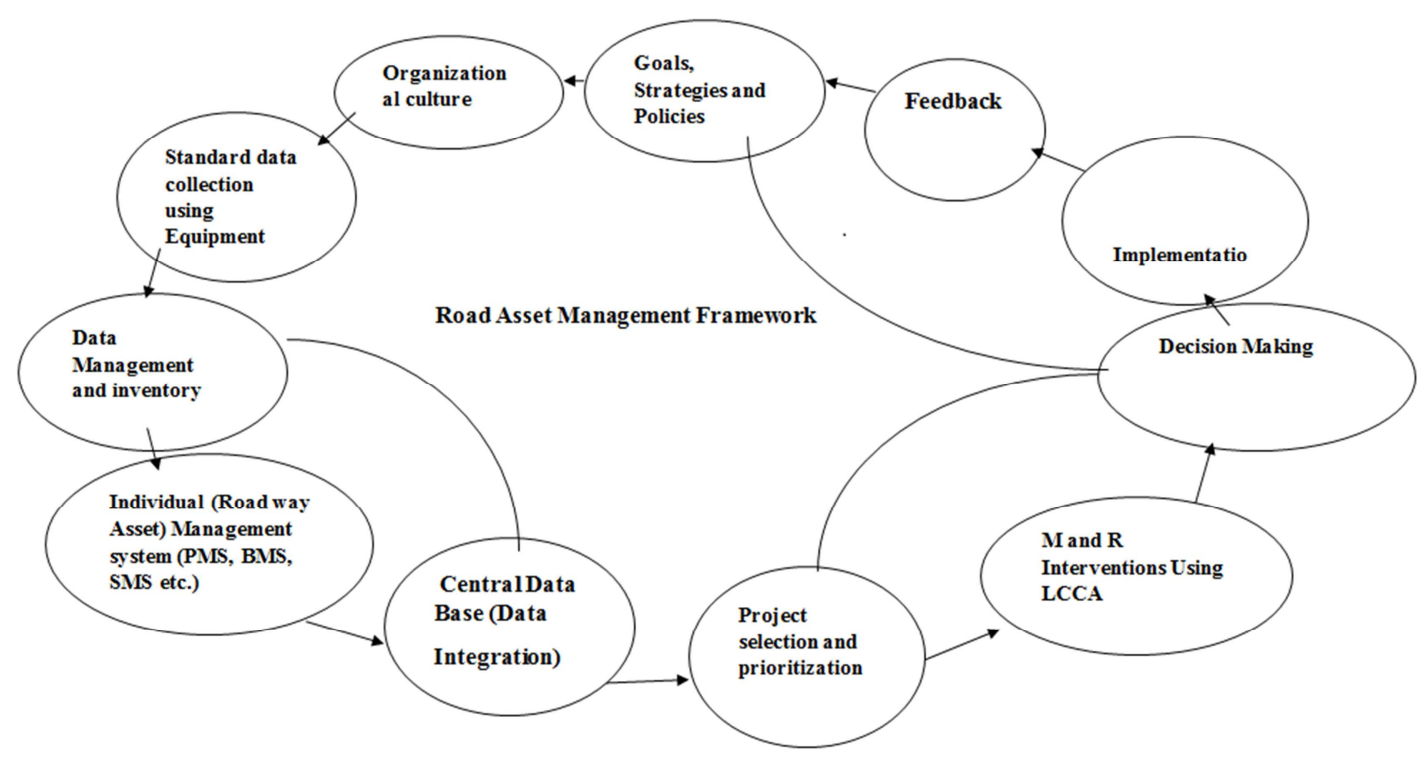

(a) 


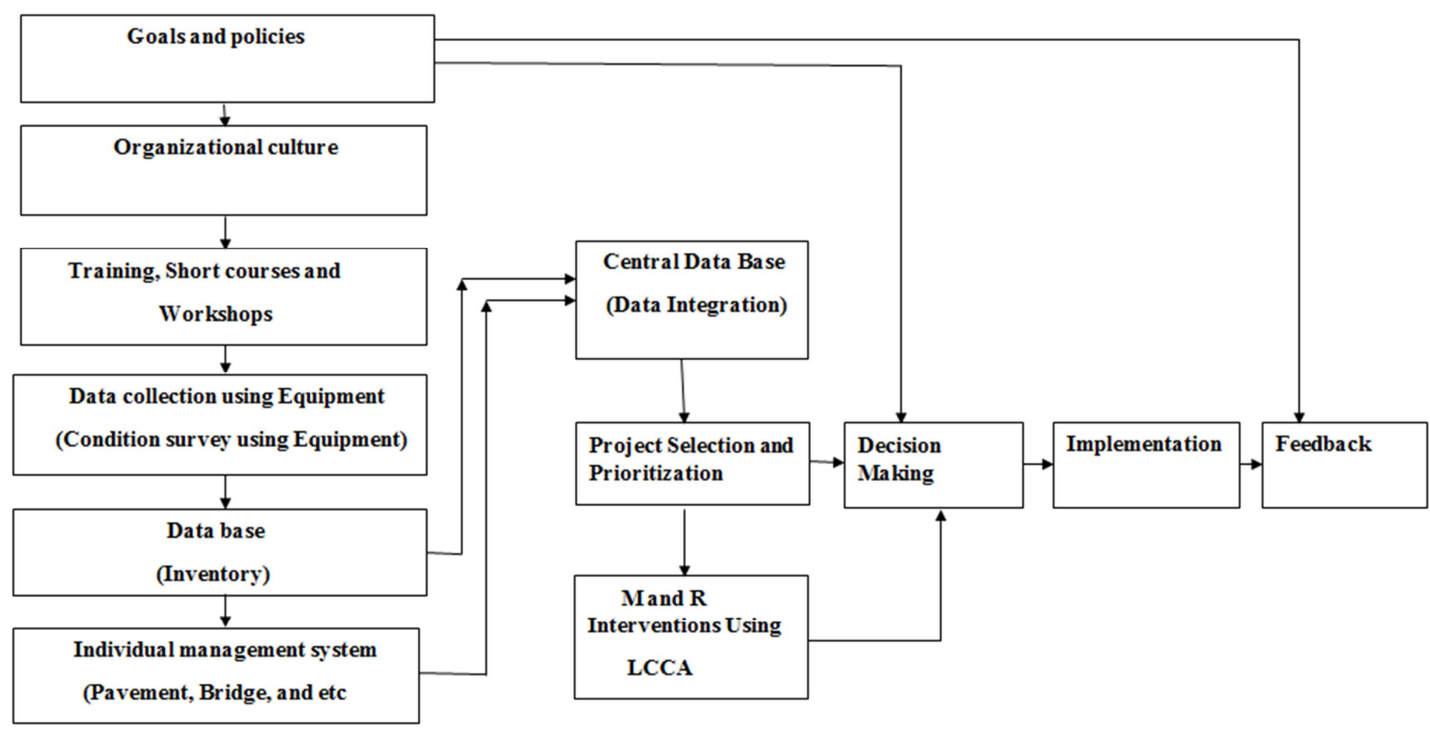

(b)

Figure 7. Road Asset Management Framework.

Proposed Framework for Effective and Efficient Asset Management Implementation.

\section{References}

[1] AASHTO (2001). Pavement Management Guide. American Association of State Highway and Transportation Officials, Washington, D. C.

[2] Asset Management Policy, Strategy and Plan. Guidelines for Developing an Asset Management Policy, Strategy and Plan. August 2004. State government of Victoria. Department for Victorian communities. 2004. www.dvc.vic.gov/local_gov.htm. Accessed June 05, 2016.

[3] Biniyam Regassa (2015) Msc thesis on Study of Performance Based Road Maintenance Contracting System for Ethiopian Federal Roads, Addis Ababa University, Addis Ababa.

[4] Dewan, S. A. 2004. Pavement Management and Asset Management Side-by-Side. 6th International Conference on Managing Pavements. Tempe, Arizona, USA.

[5] ERA, assessment of 17 years performance of road sector development program (2014), Addis Ababa.

[6] Federal Negarit Gazette (2014) Federal integrated infrastructure development coordinating agency establishment proclamation, proclamation No. 857/2014, Addis Ababa.

[7] FHWA (1999). “Asset Management Primer", Federal Highway Administration, Office of Asset Management, Washington, DC.

[8] FHWA (2001) (b). "Data Integration Primer", Office of Asset Management, Washington, DC.

[9] FHWA (2001) (f). "Data Integration for Asset Management. Forum and Peer Exchange", Proceedings of the Forum and Peer Exchange, Chicago, IL.

[10] Flintsch G. W., Dymond, R. and Collura, J. (2004). "Pavement Management Applications using Geographic Information Systems", National Cooperative Highway Research Project
20-5, Synthesis Topic 34-11, Washington, DC.

[11] Gerardo W. Flintsch and J. W. Bryant, Jr. 2006. Asset Management data collection for supporting decision making process.

[12] Haas, R., Hudson, W. R., and J. Zaniewski. Modern Pavement Management. Kreiger Publishing Company, Florida. 1994.

[13] Hudson, W. R., Haas, R., and Uddin, W. (1997). "Infrastructure Management Systems," McGraw Hill Publishers, New York, NY.

[14] L. Ma, Y. Sun, and J. Mathew (2007) Asset Management Processes: Modeling, Evaluation and Integration, conference of world congress for Engineering Asset Management (WCEAM), Harrogate, UK.

[15] OECD. Asset Management for the Road Sector. OECD Publication, 2001.

[16] PIARC, Asset Management Practice, Technical Committee C4.1 Management of road infrastructure assets, Paris, 2008.

[17] Peregrine Systems Inc. Asset Management product Brief, (2000), "The benefits of Asset Management," Peregrine systems, the infrastructure management company, Irvine California.

[18] Richard E. Brown and Bruce. G. Humphrey, (2005) Asset Management Transmission and Distribution 2005.

[19] S. Ramakrishna, B. Amol, V. K, Prasanna,(2009) An architecture of a workflow system for integrated Asset Management in the smart oil field domain chevron funded center for interactive smart oil field technologies, university of southern California, Losangeles.

[20] VA. Alexandria, (2002), Research Priorities for successful Asset Management: a workshop Water Environmental Research Foundation London. 